\title{
Parametric Finite Element Analysis for the Modular Expansion Device of Long-Span Bridge
}

\author{
Fang Wu, Jianwu Pan, and Minghua Zhou
}

\begin{abstract}
In order to research the cause of disease in modular expansion joints, in this paper, based on the secondary development, a general static analysis program has been compiledto facilitate the analysis of the integral finite element model of modular expansion joints. On this basis, the parameter analysis of modular expansion joints has been carried out using this program, mainly discuss the factor that affect the horizontal displacement of lamella. Moreover, the effect of the failure of sliding spring and control spring has been analyzed. The formula for the horizontal displacement of lamella is presented. The results show that the rigidity of control system and the condition of edge beam have a larger influence on horizontal displacement of lamella, then is friction coefficient of contact element, pre-tightening force and stiffness of sliding spring. Moreover, the failures of sliding spring and control spring are all close to the end of sliding. The research can provide scientific basis for the disease mechanism and the disease control of modular expansion joints.
\end{abstract}

Index Terms - Control spring, Lamella, modular expansion joints, sliding spring.

\section{INTRODUCTION}

The elastic control system of the modular expansion device has good performance [1], so it is widely used in bridges at home and abroad, such as Runyang Long-span Bridge, Jiangyin Long-span Bridge, Nanjing Second Yangtze River Bridge,Hong Kong Tsingma Bridge, Normandy Bridge in France, Gante Bridge in swiss, Korea Incheon Bridge [2]-[4], etc. Due to the lack of understanding of the working principle and failure mechanism of the modular expansion device, there are many problems in the use of the bridges. The modular expansion needs to be replaced once in 5-6 years, even though the original design working life is not less than 15 years. This has resulted in a great waste of resources and economic losses, and it also leaves a danger to traffic safety and bridge life. Many scholars at home and abroad have studied the disease mechanism of modular expansion device. Sun used finite element software to perform the horizontal dynamic analysis of the modular expansion device, the influence of wheel impact on lamella beam was analyzed. The research showed that when the speed is less than $60 \mathrm{~km} / \mathrm{h}$, the horizontal impact of the wheel on lamella beam is very small. Only when the vehicle speed reaches $100 \mathrm{~km} / \mathrm{h}$, will its horizontal impact force on lamella beam be considered [5], [6]. B. Zuada Coelho conducted a dynamic study on the

Manuscript received October 9, 2018; revised May 2, 2019.

Fang Wu is with Nanjing University of Aeronautics and Astronautics, Jiangsu Province, China.

Jianwu Pan is with Department of Civil Engineering, Nanjing University of Aeronautics and Astronautics, Jiangsu Province, China (e-mail: panjianwu@nuaa.edu.cn)

Minghua Zhou is with School of Civil Engineering, Southeast University, Jiangsu Province, China. disease of the modular expansion device, and the research showed that the impact load of vehicle has a great influence on the strain of lamella beam [7], [8]. The above research results discussed the cause of disease of modular expansion device from various aspects. However, in the actual use, the failure of the expansion device begins with the damage of sliding spring and control spring. If it is not maintained and replaced in time, the lamella beam will bend and break, and then the entire expansion device needs to be replaced [9], [10]. Therefore, it is necessary to study the factors influencing the horizontal displacement of lamella beam and the failure mechanism of sliding springs and control springs. But at present, there is no software to conduct 3 Three-dimensional integral analysis of the modular expansion device, and more detailed parameter analysis has not been found in the relevant literature, but all these are necessary to analyze the cause of disease. So, in this paper, the failure mechanism of the modular expansion device is studied by compiling a general calculation program. Fig. 1 shows the disease of the expansion device [11]-[16].

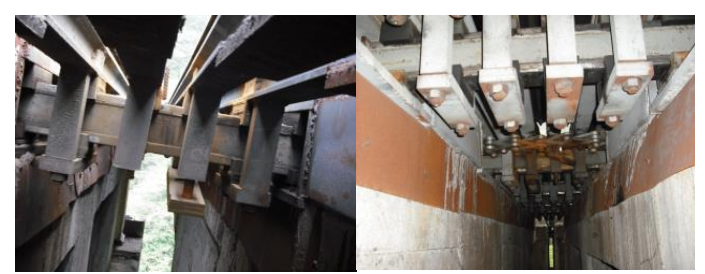

(a)

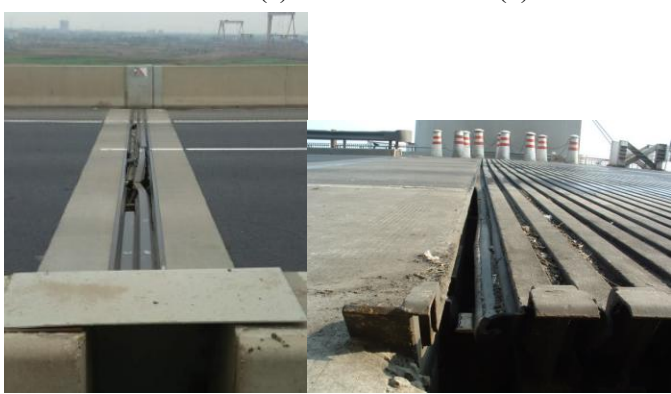

(c)

(d)

Fig. 1. Disease of the expansion device.

\section{The Programming OF General CALCUlation PROGRAM OF MODULAR EXPANSION DEVICE}

\section{A. Establish the Parametric Finite Element Model}

The modular expansion device is mainly composed of joist beam, lamella beam, edge beam, rubber seal, joist beam box, stirrup, bearing spring, sliding spring and control spring (Fig. 2). Parametric finite element model was 
established with ANSYS APDL(Fig. 3). In the process of modeling, the secondary structure was simplified. BEAM188 Element was used to simulate joist beam, lamella beam, sliding spring box and sliding spring. Control spring was simulated by COMBIN14 Element. The contact friction between the sliding springs and joist beam was simulated by CONTAC178 Element. And Lagrange multiplier algorithm was adopted. The section types of lamella beam, joist beam and edge beam are shown in Fig. 4.

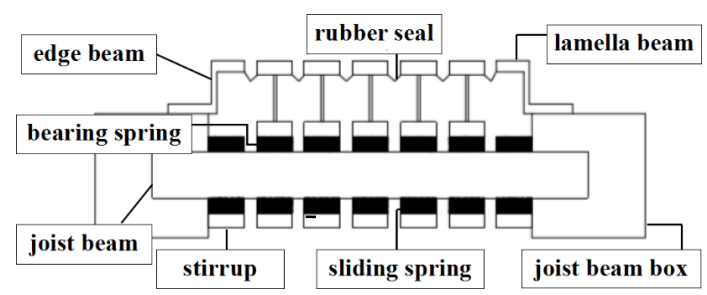

Fig. 2. Components of the modular expansion device.

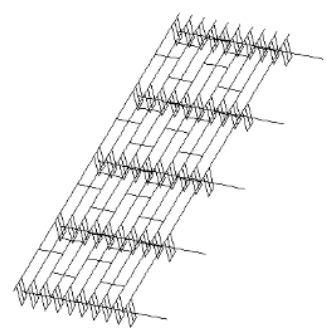

Fig. 3. Finite element model for modular expansion joints.

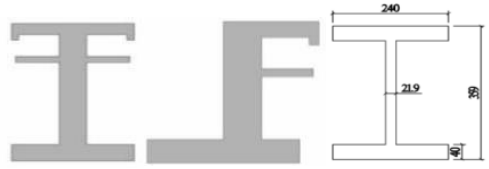

Fig. 4. Section shape of Lamella beam, edge beam, joist beam.

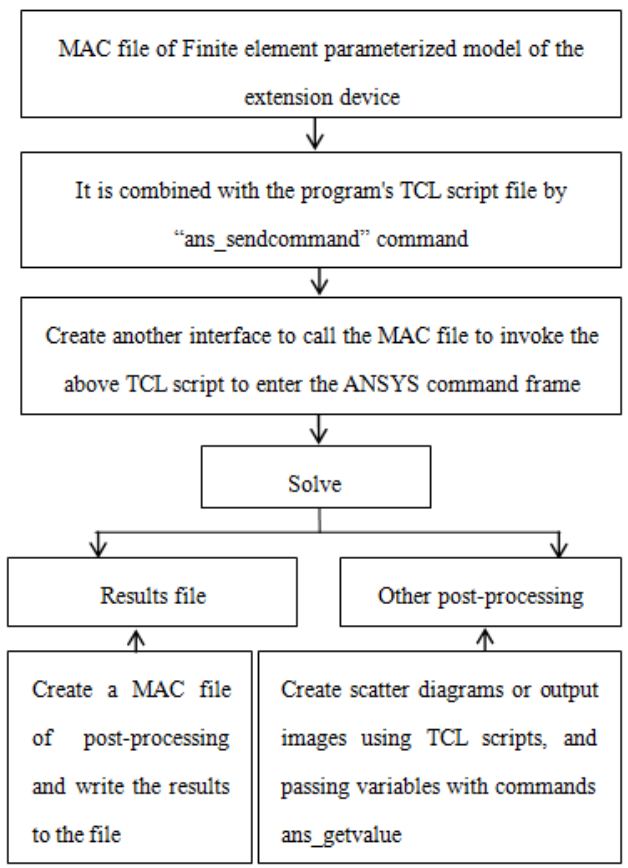

Fig. 5. Program block diagram.

One end of the joist beam is fixed and all degrees of freedom are constrained, the other end is the sliding end and all degrees of freedom are constrained except that along the bridge.

\section{B. Establish an Interactive Interface by TCL/TK}

\section{1) Overview of the program interface}

Using the interaction between ANSYS and TCL/TK, establish the program interface shown in Fig. 4, through this interface, the model parameters can be changed easily and the finite element analysis can be carried out quickly. Parameter classification was realized by Label frame. In the TCL script file, the Place command is used to determine the location, width, and height of each element. Create a new font with the Set and Font create commands. The main command used in the interaction between TCL and ANSYS are: Ans sendcommand, which calls commands from ANSYS into TCL; Ans_getvalue, which is used in the post processing to pass variables from ANSYS to TCL.In the post-processing section, given the output efficiency, the text output does not call the word document, but simply output the TXT file. The graphical output does not call an excel document, but using the BLT control to generate the scatter diagram directly. The program block diagram is shown in Fig. 5.

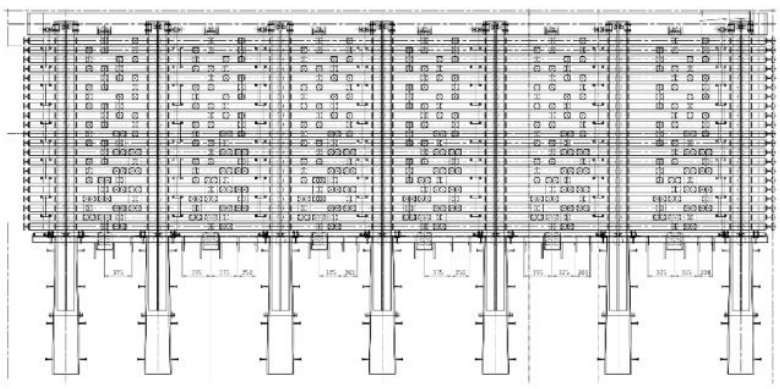

Fig. 6. Plan view of 22-gap joint with mageba elastic control system (Nanjing).

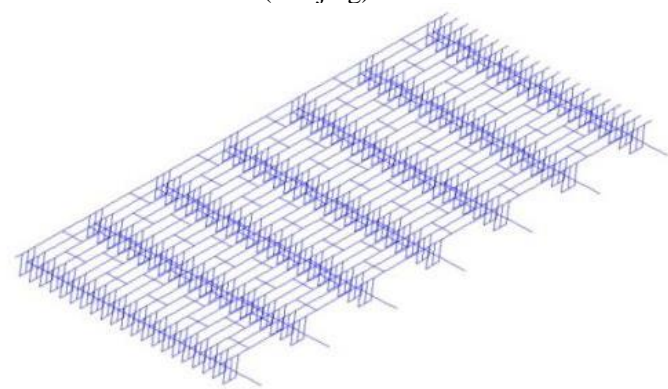

Fig. 7. Finite element model for modular expansion joints of some bridge in Korea.

Through the program interface, users can customize the size of the model, the real constant and load,etc, and a series of post-processing results are obtained quickly. For example, the $\mathrm{X}$ deformation scatter diagram of Lamella beam and joist beam; Compression deformation scatter diagram of the sliding springs; Shows the overall deformation; Shows Von Mises Stress of Lamella beam; The Von Mises Stress of Lamella beam when contact element is deleted one by one; The force on the control springs and so on. All major post-processing information can be formed into a briefing and stored in text files.

\section{2) Example}

Fig. 6 shows the modular expansion device of Nanjing second yangtze river bridge. There are 7 joist beams and 21 
Lamella beams. The distance of the joist beams is 1.4 meters, and of the Lamella beams is 0.2 meters. The stiffness of the control spring is $1 \mathrm{e} 7$, and the friction coefficient of contact element is 0.03 . The section radius of the sliding springs are 0.02 . The vertical load of the bridge is $2.52 \mathrm{e} 4$, and the horizontal displacement load is $0.1 \mathrm{~m}$ (Fig. 7).

After clicking the "x-direction deformation of Lamella beam" button, the program will draw the horizontal displacement curve of the current model automatically. The $\mathrm{x}$-coordinate of the curve is the number of Lamella beam and the $y$-coordinate of the curve is the horizontal displacement $(\mathrm{m})$ of Lamella beam. Minus indicates that the direction of the horizontal displacement is the free end moving towards the sliding end. The horizontal displacement of Lamella beam is uniform, and every Lamella beam is involved in the work.

After clicking the "Von Mises Stress of Lamella beam" button, the program will displays the section shape of the entire model and the Von Mises Stress nephogram of the model automatically. The Von Mises Stress of Lamella beam is $0.395 \mathrm{e} 9 \mathrm{~Pa}$, much less than its yield strength.

\section{The PARAmeters That May CAUSE THE Disease of THE MODULAR EXPANSION DEVICE WERE ANALYZED BY FINITE ELEMENT METHOD}

The following analysis does not use the modular expansion device model of the Korean bridge, instead, a simple finite element model is established for analysis. There are 5 joist beams and 10 Lamella beams. The distance of the joist beams is 1.4 meters, and of the Lamella beams is 0.2 meters. The stiffness of the control spring is $1 \mathrm{e} 5$, and the friction coefficient of contact element is 0.01 . The section radius of the sliding springs are 0.02 . The vertical load of the bridge is $2.8 \mathrm{e} 4$, the Pre-tightening force is $100 \mathrm{~N}$, and the horizontal displacement load is $-0.1 \mathrm{~m}$ (moving from sliding end to fixed end) (Fig. 3).

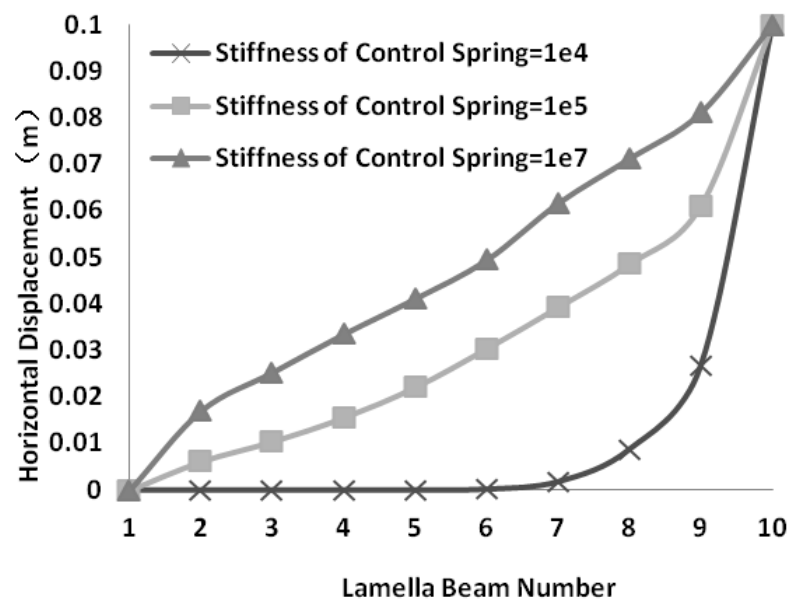

Fig. 8. Horizontal displacement curve of lamella under different stiffness of control spring.

\section{A. Stiffness of the Control Spring}

When the shrinkage of the expansion device is $100 \mathrm{~mm}$, the displacement of the lamella beam gradually increases unevenly from the fixed end to the sliding end. When the stiffness of the control spring is 1e4, only a few lamella beams near the sliding end move, and the lamella beam near the fixed end does not work.Due to the uneven horizontal displacement of the lamella beam, the deformation of control spring is not uneven, so, the control spring near the sliding end is more easy to damage. As shown in Fig. 8, when the stiffness of the control spring increases to $1 \mathrm{e} 5$ and $1 \mathrm{e} 7$, each lamella beam moved. And within a certain range, the greater the spring stiffness, the greater the horizontal displacement of the lamella beam. However, when the stiffness of the control spring is particularly large, the horizontal displacement and equivalent stress of the lamella beam are significantly increased, as shown in Fig. 9.

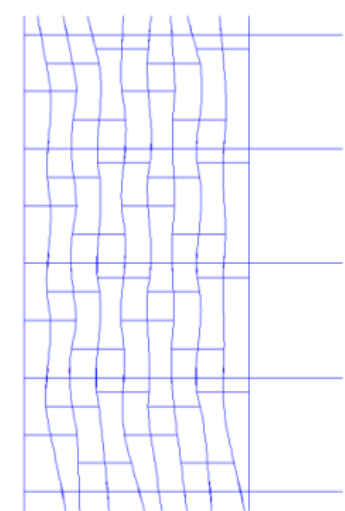

Fig. 9. Too large stiffness of control spring.

Therefore, in the design of different scales of modulus expansion devices, The optimum stiffness of the control spring or the horizontal stiffness of the middle lamella beam can be selected by considering the deformation of the control spring and the deformation of lamella beam.

\section{B. Uneven Arrangement of the Control Springs}

As mentioned above, when the control springs are uneven arranged, the displacement of the lamella beam is uneven. Fig.10 shows the change of horizontal displacement of the lamella beam when the control springs are uneven arranged. When the control springs are arranged unevenly(The number of control springs from fixed end to sliding end increases gradually or the stiffness of that decrease gradually.), there are more lamella beams are working.

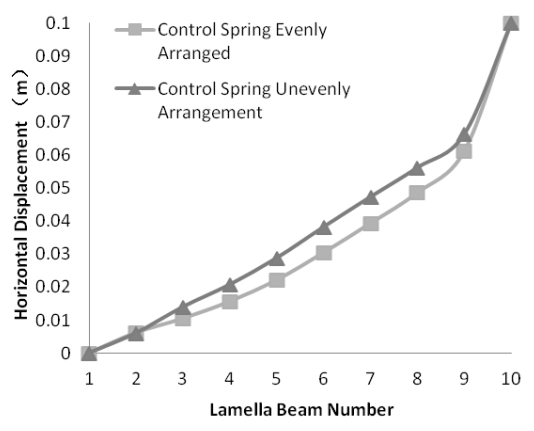

Fig. 10. Horizontal displacement curve of lamella under Uneven arrangement of control spring. 


\section{Friction Coefficient of Contact Element (MU)}

As shown in Fig. 11, the friction coefficient of the contact element varies with the horizontal displacement of the Lamella beam. When decrease the friction coefficient of contact element (MU), the displacement of Lamella beam will increase. The smaller the friction coefficient, the smaller the friction resistance, and the larger the horizontal displacement of Lamella beam. Therefore, the change of horizontal displacement of Lamella beam is sensitive to the change of friction coefficient (MU).

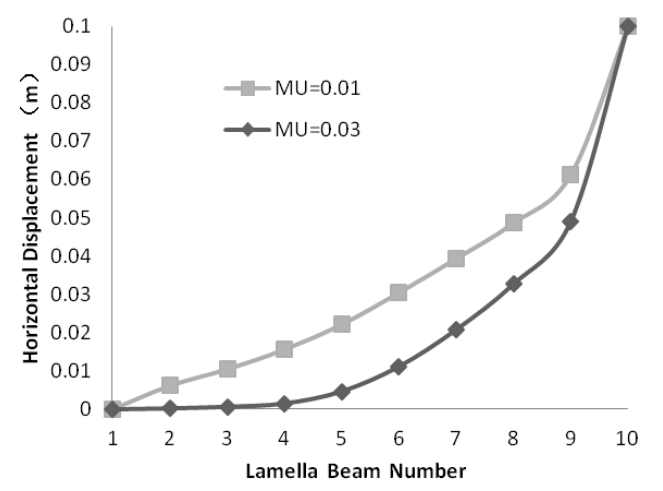

Fig. 11. Horizontal displacement curve of lamella under different MU.

\section{Pre-tightening Force}

Fig.12 shows the change of horizontal displacement of Lamella beams with different pre-tightening forces. When the pre-tightening force increases, the friction resistance of Lamella beam increases and the horizontal displacement decreases. Therefore, the pre-tightening force has some influence on the horizontal displacement of Lamella beam.

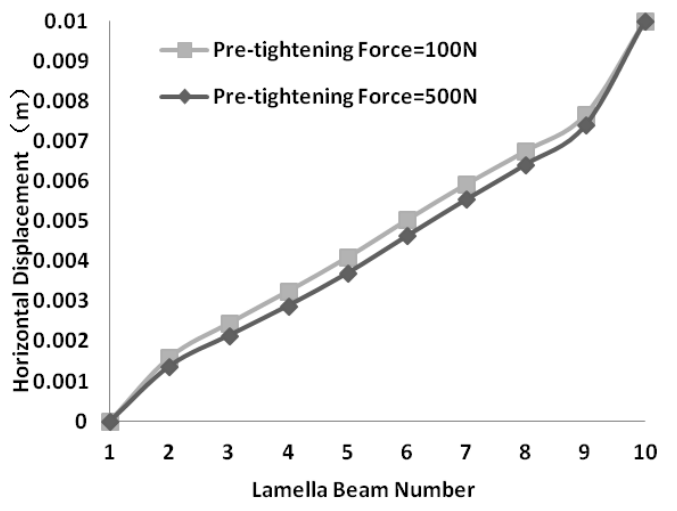

Fig. 12. Horizontal displacement curve of lamella under different pre-tightening force.

\section{E. Stiffness of Sliding Springs}

Fig.13 shows the change of horizontal displacement of Lamella beam with different stiffness of sliding springs. The horizontal displacement of Lamella beam is more uniform when the stiffness of sliding spring is $1 \mathrm{e} 6$. In the case of applying only the pre-tightening force, when the stiffness of sliding springs is increased, the pre-tightening force of that will increases, so the friction resistance of Lamella beam increases, and the horizontal displacement decreases. As a result, the stiffness of the sliding springs affects the horizontal displacement of Lamella beam.

During construction, the pre-tightening force is applied by tightening the stirrup. As the stiffness of bearing springs is much larger than that of sliding springs, the stiffness of bearing spring has little influence on pre-tightening force, so it has little influence on the horizontal displacement of Lamella beam. However, the ratio of the stiffness of bearing spring and the stiffness of sliding spring should be ensured to prevent the impact of the instantaneous disengagement and closure of sliding spring under the vehicle load.

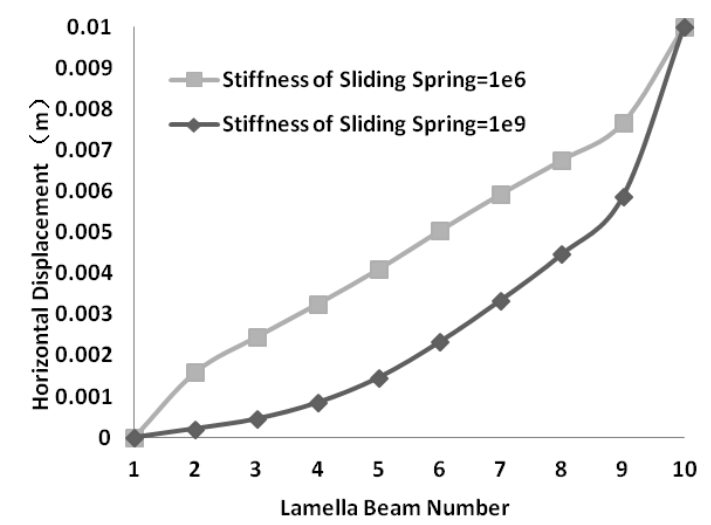

Fig. 13. Horizontal displacement curve in different stiffness of sliding spring.

\section{F. Analysis of the Most Important Position of the Bearing Spring}

Remove the contact element one by one, and the changes of Von MIses steess of Lamella beams are analyzed to find out the location of the bearing spring that affects the Lamella beam most.

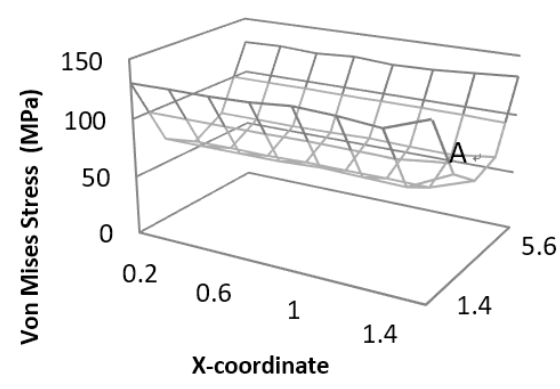

Fig. 14. Maximum Von Mises stress of lamella when delete the contact element one by one.

Fig. 14 shows Von Mises stress of Lamella beams when the contact element are removed one by one. When the contact element near the bottom of the sliding end is removed (i.e., simulating the bearing spring fails), the Von Mises stress of Lamella beams is the maximum. That is, the bearing spring which has the most influence on Lamella beams is located near the sliding end (Point A). Fig. 15 shows the FN of bearing spring, and the position of bearing spring which subjected to the maximum vertical force is close to the sliding end at point B. Fig. 16 shows FS of the bearing spring. The shear distribution of the bearing spring is basically consistent with the vertical force distribution. The bearing spring under the maximum shear force and that under the maximum vertical force are the same one, that is, the bearing spring at the position of point $\mathrm{C}$. The bearing spring with the largest impact on Von Mises stress of 
Lamella beams is not at the same position as the bearing spring with the largest stress, but in common, both of them are close to the sliding end.

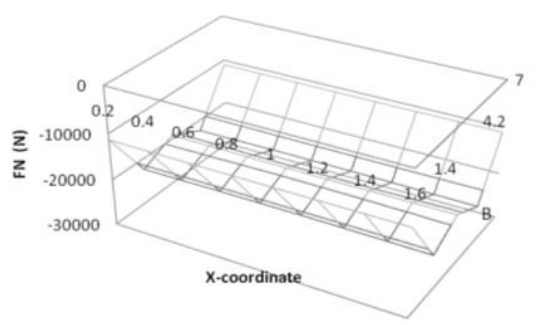

Fig. 15. FN of sliding spring.

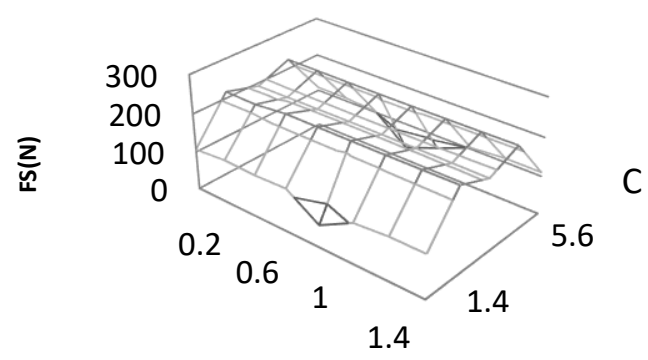

Fig. 16. FS of sliding spring.

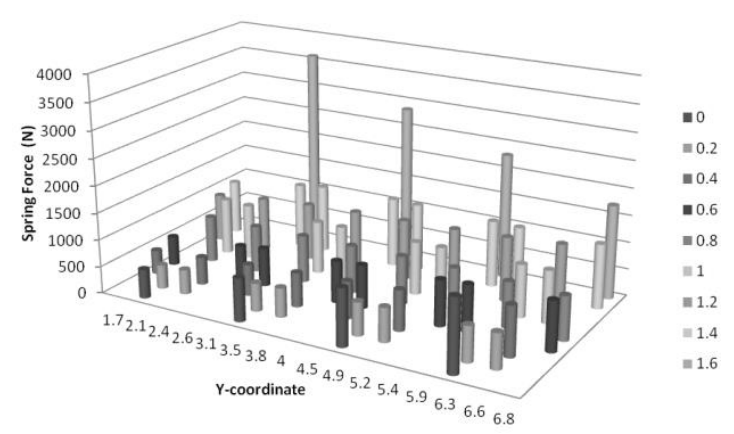

Fig. 17. Spring force of control spring.

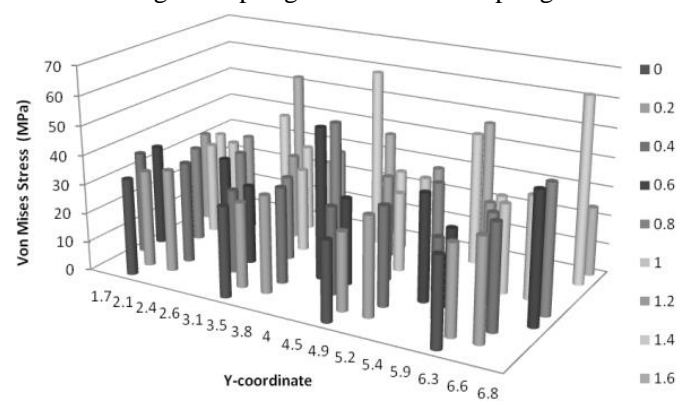

Fig. 18. Maximal von mises stress of lamella when remove the control spring one by one.

\section{G. Analysis of the Most Important Position of the Control Spring}

As shown in Fig. 17, the spring force of the displacement control spring is basically unequal, the control spring with the largest force is located at the lower end of the expansion device closest to the sliding end.

Fig. 18 shows Von Mises stress of Lamella beams when the control springs are removed one by one. When the control spring near the top of the sliding end is removed (i.e., simulating the control spring fails), the Von Mises stress of Lamella beams is the maximum.
The control spring with the largest impact on Von Mises stress of Lamella beams is not at the same position as the control spring with the largest stress, but both of them are close to the sliding end. The difference is that the control spring with the largest stress is located at the lower end of the expansion device, while that with largest impact on Von Mises stress of Lamella beams is located at the upper end of the expansion device.

\section{CONCLUSION}

In this paper, the MSSS program was developed first, and the possible causes of the disease of the modular expansion device were studied by parametric finite element analysis. The main conclusions are as follows:

(1) The horizontal displacement of Lamella beams is sensitive to the stiffness and arrangement of the control spring; It is sensitive to friction coefficient and pre-tightening force of contact elements; The stiffness of the sliding spring has a certain influence on the pre-tightening force, so it also has an influence on the horizontal displacement of Lamella beams.

(2) The stiffness of control spring is different in expansion device of different scales. On the premise that the stress of the Lamella beam is within the safe range, the higher the spring stiffness of the control springs, the greater the degree of involvement of Lamella beams. The control spring is not evenly arranged, so that the horizontal displacement of Lamella beams is more even.

(3) The smaller the friction coefficient, the less easily premature failure of the expansion device. The stiffness of the sliding spring should also be controlled to prevent it from slipping away.

(4) The most important bearing springs and control springs in the modular expansion device are located at the sliding end. That is, the bearing springs and the control springs at the sliding end are more likely to be damaged first, and the damage has a great impact on other components.

\section{ACKNOWLEDGMENT}

This study was funded by National Key Research Program of China (2016YFC0701400) and Transport research project at Jiangsu province funding project (2013T09).

\section{REFERENCES}

[1] Control Systems of Modular Expansion Joints, Techincal Report of Mageba Ltd, 2015.12.

[2] Mageba Modular Expansion Joints - The Benchmark for Large Movements, Techincal report of Mageba Ltd, 2015.12.

[3] Thomas SPULER. "Bridge components to satisfy the demanding requirements of modern bridge," in Proc. 34th IABSE Symposium, Venice, Italy, 2010.

[4] L. G. Huang, "Study on performance evaluation and disease control of large span steel bridge expansion joint," Southeast University, 2017

[5] Z. J. Liu, "Study on the disease mechanism of the modulus expansion joint of a bridge," Urban Roads Bridges and Flood Control, pp. 205-208+22, July, 2016.

[6] Z. F. Sun, S. H. Wang, H. Wu, and L. Bin, "Horizontal dynamic analysis of modular bridge expansion joints," Highway Engineering. vol. 39, no. 3, pp. 25-28, 2014.

[7] Z. O. He, W. Ye, and Y. Chu, "Analysis of fatigue life of modular bridge expansion joints," Journal of South China University of Technology, vol. 44, no. 4, pp. 91-100, 2016. 
[8] B. Z. Coelho, A. H. J. M. Vervuurt, W. H. A. Peelen, and J. S. Leendertz, "Dynamics of modular expansion joints: The Martinus Nijhoff bridge," Engineering Structures, p. 48, 2013.

[9] JTG B01-2014 Technical Standards for Highway Engineering, People's transportation press.

[10] DB32/T3154 - 2016 Maintenance and Replacement of Highway Bridge Expansion Equipment, People's Transportation Press.

[11] Game creation room, APDL Parametric Finite Element Analysis Technique and Its Application Examples, Beijing: China Water Conservancy and Hydropower Press, 2004, ch.3.

[12] J. K. Ousterhout, K. Jones, and Y. Z. Zang, Tcl / Tk Portal Classic (Second Edition). Beijing: Tsinghua University Press, 2010, ch.10.

[13] Z. D. Chang, D. Xue, and Q. J. Wang, "Disease and prevention measures of modular expansion joints," Shanxi Architecture, vol. 40, no. 23, pp. 212-213, 2014.

[14] J. B.Wang, "A brief discussion on the failure analysis and maintenance technology of the modular bridge expansion joints," Science and Technology Horizon, no.25, pp.324-325, 2016.

[15] X. Ming, H. Yueping, D. D, He, and M. H. Zhou, "Experimental research on performance of shear displacement springs for modular expansion joints," Highway Traffic Technology (Application Technology Version), vol. 13, no. 4, pp. 185-188, 2017.

[16] X. Ming, Y. P. Huang, D. D. He, and M. H. Zhou, "Experimental study on performance control of compression control elements for modular expansion joints," Modern Transportation Technology, vol. 13 , no. 4 , pp. $39-42,2016$

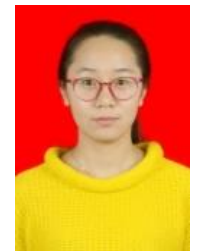

Fang Wu is with the Department of civil engineering, Nanjing university of aeronautics and astronautics, Jiangsu province, China.

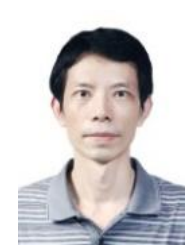

Jianwu Pan is with the Department of Civil Engineering, Nanjing University of Aeronautics and Astronautics, Jiangsu Province, China. He was born in 1976. The last degree is doctor, in School of civil engineering, southeast university.

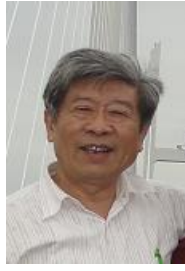

Minghua Zhou is with School of Civil Engineering, Southeast University, Jiangsu province, China. He was born in 1943. He is retired teacher of Civil Engineering College. 